\title{
Root uptake of uranium by a higher plant model (Phaseolus vulgaris) - bioavailability from soil solution
}

\author{
L. Laroche, P. Henner, V. Camilleri, M. Morello and J . Garnier-Laplace \\ Laboratory of Radioecology and Ecotoxicology, Institute for Radioprotection and Nuclear \\ Safety, DEI/SECRE/LRE, Cadarache, Bd. 186, BP. 3, 13115 St-Paul-lez-Durance Cedex, \\ France, e-mail: laetitia.laroche@irsn.fr
}

\begin{abstract}
Uranium behaviour in soils is controlled by actions and interactions between physico-chemical and biological processes that also determine its bioavailability. In soil solution, uranium (+VI) aqueous speciation undergoes tremendous changes mainly depending on $\mathrm{pH}$, carbonates, phosphates and organic matter. In a first approach, plants (Phaseolus vulgaris) were grown using hydroponics to allow an easy control of the composition of the exposure media. The latter, here an artificial soil solution, was designed to control the uranium species in solution. A geochemical speciation code was used to perform the solution speciation calculations. On this theoretical basis, three domains were defined for short-duration well-defined laboratory experiments in simplified conditions: $\mathrm{pH} 4.9,5.8$ and 7 where predicted dominant species are uranyl ions, hydroxyl complexes and carbonates respectively. For these domains, the influence of plant growth stage on transfer was determined. The Free Ion Model (or its derivated the Biotic Ligand Model) was tested to determine if $U$ uptake was governed by the free uranyl species or if other metal complexes could be assimilated. The effect of different variables on root assimilation efficiency and phytotoxicity was explored: presence of ligands such as phosphates or carbonates and competitive ions such as $\mathrm{Ca}^{2+}$ at the $3 \mathrm{pHs}$.
\end{abstract}

\section{INTRODUCTION}

Uranium exists naturally in the earth's crust at the mean content of $2.5 \mathrm{mg} \mathrm{kg}^{-1}$. Its behavior in soils is controlled by actions and interactions between physico-chemical processes (speciation in solution and binding with mineral/organic particles) and biological processes (soil invertebrates, root activity, micro organisms activities, etc...) that also determine the bioavaibility of the metal. Indeed, the speciation of the pollutant in the exposure medium is the first factor regulating its bioavailability and so its bioaccumulation in organisms. In soil solution, uranium is present at the $(+\mathrm{VI})$ oxidation state mainly with the uranyl ion $\left(\mathrm{UO}_{2}{ }^{2+}\right)$ that can be associated with organic matter, carbonates, phosphates, clays, etc... [1].

The study of the movement of uranium from soil to edible vegetation through root uptake is very important in determining its environmental behaviour, especially when considering food chain transfers. However, some factors can limit the uptake of uranium by plants. Indeed, it is now established that the speciation of a metal is an important factor controlling metal bioavailability and toxicity in living organisms. The Free Ion Activity Model (FIAM), first developed for aquatic species, postulates that toxicity of a metal is generally correlated with the concentration of the free metal ion (uranyl ion in the case of uranium) [2]. However, some exceptions to this FIAM have been reported [3, 2]. Previous studies [4] have shown that the free ion uranyl cation $\left(\mathrm{UO}_{2}{ }^{2+}\right)$ was the species of uranium readily taken up and translocated at $\mathrm{pH}<5.5$. Moreover hydroxocomplexes or complexes of uranium with carbonates are not appreciably accumulated in plant shoots. 
So, the objective of this study was to determine the uptake and translocation of uranium in the Common Bean (Phaseolus vulgaris) from uranium contaminated hydroponics solutions at different pHs and growth stages of plants. Speciation and also bioavailability of uranium is affected by different factors where $\mathrm{pH}$, ligands and competitive ions play a major role. Their influence was investigated during short-term experiments.

\section{MATERIAL AND METHODS}

\subsection{Nutrient solution}

On the basis of the nutrient solution currently used in hydroponic culture (diluted Hoagland's solution), a nutrient solution was designed to satisfy both nutritional requirements of plants and uranium speciation in solution: $3.0 \mathrm{mM} \mathrm{KNO} 3,0.25 \mathrm{mM} \mathrm{Ca}\left(\mathrm{NO}_{3}\right)_{2}, 0.15 \mathrm{mM} \mathrm{MgSO}_{4}, 5 \mu \mathrm{M}$ Fe-EDTA, $25 \mu \mathrm{M} \mathrm{KCl}$, $1 \mu \mathrm{M} \mathrm{MnSO}_{4}, 0.25 \mu \mathrm{M} \mathrm{ZnSO}_{4}, 0.1 \mu \mathrm{M} \mathrm{CuSO}_{4}, 0.1 \mu \mathrm{M} \mathrm{NiSO}_{4}, 0.1 \mu \mathrm{M} \mathrm{Na}_{2} \mathrm{MoO}_{4}, 0.1 \mu \mathrm{M} \mathrm{H}_{3} \mathrm{BO}_{3}$. Phosphorus source was excluded from the solution to prevent phosphate-uranium complexes formation.

To predict complexes that can be formed between uranium and the elements of the nutrient solution, a geochemical speciation model (CHESS) was employed. The database used was reviewed and modified to improve its coherency and perform the solution speciation calculation [5]. Simulation with CHESS model indicates 3 domains of dominant uranium species: at $\mathrm{pH} 4.9$, about $64 \%$ of the uranium in the solution was present as the free uranyl cation $\left(\mathrm{UO}_{2}{ }^{2+}\right)$, at $\mathrm{pH} 5.8,60 \%$ as hydroxo - complexes and at $\mathrm{pH} 7$, uranium was present at $80 \%$ as carbonate complexes. These $3 \mathrm{pHs}$ determined 3 contrasted conditions of uranium speciation that will be studied.

\subsection{Plant culture}

Seeds of beans were first germinated on moistened filter paper for 4 days and then transferred to pots containing vermiculite. After about 7 days (seedlings growth stage), plants were removed from the germination pots and the vermiculite entangled in the roots was manually removed in large basins containing the nutrient solution. They were immersed in basins containing nutrient solution and aerated in continuous. Phosphorus, which was excluded from nutrient solution was vaporised on leaves during growth $(0.5 \mathrm{mM})$. After 3 days, nutrient solution was replaced and its $\mathrm{pH}$ was maintained constant at $\mathrm{pH} 4.9,5.8$ or $7( \pm 0.05)$ by titration with nitric acid $(0.1 \mathrm{M})$ during 2 days. All germinations, cultures and experimentations were realised in a culture chamber with controlled temperature $\left(21^{\circ} \mathrm{C}\right.$ during night period and $24^{\circ} \mathrm{C}$ during the photoperiod), $64 \%$ humidity and a photoperiod of 16 hours.

\subsection{Experiments}

\subsubsection{Generalities}

During experiments, $\mathrm{pH}$ of nutritive solution was maintained by titration with nitric acid $(0.1 \mathrm{M})$. Before the introduction of plants pots containing the contaminated nutrient solution, the system was equilibrated during 36 hours. At the end of each experiment, bean plants were rinsed twice by uncontaminated fresh nutrient solution and then with deionised water, to remove residues of uranium solution and weakly adsorbed uranium around roots. Roots were separated from shoots and leaves and were dried during 3 days at $60^{\circ} \mathrm{C}$ to determine their dry weight. Parts of plants were ashed (first step at $200{ }^{\circ} \mathrm{C} / 3$ hours and second step at $550^{\circ} \mathrm{C} / 20$ hours) and dissolved in nitric acid $\left(2 \mathrm{ml}\right.$ of $\left.69 \% \mathrm{HNO}_{3}\right)$. After evaporation, the residue was redissolved in $10 \mathrm{~mL} 2 \%$ nitric acid to quantify the amount of uranium in 
bean roots with ICP-AES analyses for short term exposure or redissolved in $1 \mathrm{~mL}$ of nitric acid (0.01M) with addition of $19 \mathrm{ml}$ of Instagel $\stackrel{\circledR}{\Omega}$ scintillation cocktail (Packard Instrument, Rungis, France), to measure ${ }^{233} \mathrm{U}$ activities by liquid scintillation counting using a low background spectrometer.

\subsubsection{Uranium long-term transfer}

In these experiments, plants were exposed to ${ }^{233} \mathrm{U}$ radioisotope to profit from the best limit of detection by using liquid scintillation counting (to be able to measure uranium content in stem and leaves after translocation). Experiments were conducted during 3 days with plants at flowering and seedlings stage. After acclimatising periods, plants were transferred to pots containing $400 \mathrm{~mL}$ of nutrient solution contaminated with ${ }^{233} \mathrm{U}(250 \mathrm{nM})$, continuously aerated. Each pot was alimented by a general basin containing 5 litters of contaminated nutrient solution $(250 \mathrm{nM})$ where $\mathrm{pH}$ was maintained constant by nitric acid titration $(0.1 \mathrm{M})$.

\subsubsection{Uranium short-term transfer}

In all experiments, after acclimatising periods, 4 plants (defining 4 replicates) for each condition were transferred to pots containing $1.2 \mathrm{~L}$ of the nutrient solution contaminated with depleted uranium, uranyl nitrate $\left(\mathrm{UO}_{2}\left(\mathrm{NO}_{3}\right)_{2} .6 \mathrm{H}_{2} \mathrm{O}, 300 \mathrm{nM}\right)$, and continuously aerated. Plants at seedlings stage were exposed during 5 hours.

Effect of $\mathrm{pH}$ : $\mathrm{pH}$ effect was assessed by studying uranium concentration dependence on uranium uptake at $3 \mathrm{pHs}$. Plants were exposed during 5 hours to a range of uranium concentrations from 0.1 to about $4 \mu \mathrm{M}$ at $\mathrm{pH} 5.8$ and 7 and $4.9 \mu \mathrm{M}$ at $\mathrm{pH} 4.9$.

Effect of phosphate: Uranium speciation in solution can be affected by the presence of phosphates that can complexe uranium. Modelisation with JCHESS has permitted to determine the concentration of uranium for which there was no precipitation (saturation index $<0$ ) at the $3 \mathrm{pHs}$ studied. So plants were exposed during 5 hours to the nutrient solution with $0.3 \mu \mathrm{M}$ (no precipitation at the $3 \mathrm{pHs}$, modelisation JCHESS) at a fixed uranium nominal concentration of $0.3 \mu \mathrm{M}$ and a range of concentrations of phosphate from 0 to $15 \mu \mathrm{M}$.

\subsubsection{Calculations}

Transfer Factor (TF) is a useful parameter for the assessment of radionuclides transfer in the food chain. The TF is defined as the ratio between the concentration in plant ( $\mu$ molU/g Dry Weight) and the concentration in solution $(\mu \mathrm{molU} / \mathrm{L})$

\section{RESULTS AND DISCUSSION}

\subsection{Growth stage influence on "long term" experiments}

The potential influence of growth stage of $P$. vulgaris on uranium transfer was studied. During three days, uranium uptake and content in parts of bean were studied. Like at flowering stage, seedlings (juvenile stage) did not show any differences in uranium content of roots, stems and leaves whatever the $\mathrm{pH}$ (4.9 or 5.8). However, seedlings have more concentrated uranium in their stems and leaves than flowering stages (table 1): $4.210^{-3}$ and $3.210^{-3} \mu \mathrm{molU} / \mathrm{gDW}$ at $\mathrm{pH} 4.9$ and 5.8 respectively in stems of seedlings against $7.310^{-4}$ and $6.410^{-5} \mu \mathrm{molU} / \mathrm{gDW}$ at flowering stage. Whatever the pHs or the growth stage, $99 \%$ of uranium was recovered in the root. 
Concerning the mean Transfer Factor values, no difference has been shown between the pHs studied but TFs are greater at seedlings stage than those at flowering stage (figure 1).

Table 1. Uranium content in stems, leaves and roots of Phaseolus vulgaris at flowering and seedlings stage at the $3 \mathrm{pHs}$ studied.

\begin{tabular}{|c|c|c|c|c|c|c|}
\hline \multicolumn{7}{|c|}{ U content ( $\mu \mathrm{molU} / \mathrm{g} \mathrm{DW})$} \\
\hline & \multicolumn{3}{|c|}{ Flowering stage } & \multicolumn{3}{|c|}{ Seedlings stage } \\
\hline pH & Stems & Leaves & Roots & Stems & Leaves & Roots \\
\hline 4.9 & $7.310^{-4}\left( \pm 2.2 .10^{-4}\right)$ & $6.410^{-5}\left( \pm 2.1 .10^{-5}\right)$ & $0.157\left( \pm 6.710^{-4}\right)$ & $0.0042( \pm 0.001)$ & $1.810^{-4}\left( \pm 8.610^{-5}\right)$ & $0.29( \pm 0.051)$ \\
\hline 5.8 & $5.510^{-4}\left( \pm 6.7 \cdot 10^{-4}\right)$ & $2.610^{-5}\left( \pm 8.6 . .10^{-6}\right)$ & $0.086\left( \pm 3.710^{-4}\right)$ & $0.0032\left( \pm 6.410^{-4}\right)$ & $1.310^{-4}\left( \pm 4.610^{-5}\right)$ & $0.32( \pm 0.069)$ \\
\hline 7 & & & & $0.0032( \pm 0.0012)$ & $1.310^{-4}\left( \pm 4.610^{-5}\right)$ & $0.31( \pm 0.11)$ \\
\hline
\end{tabular}

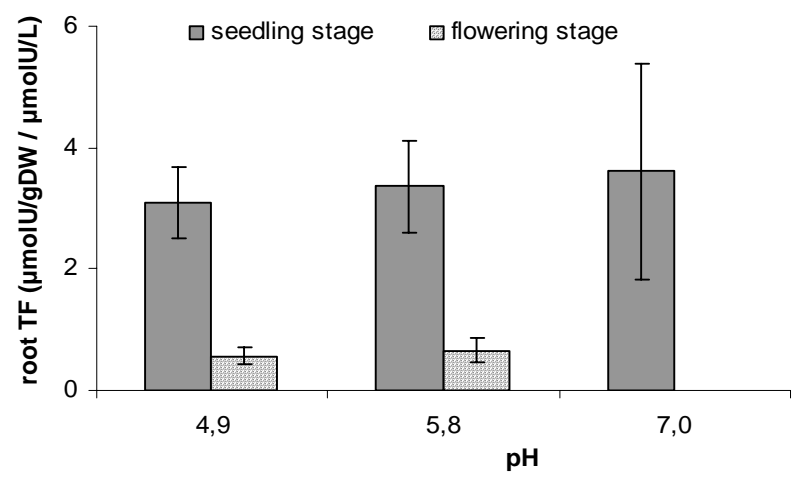

Figure 1. Mean values of root Transfer Factor (4 replicates) during exposure at pHs 4.9, 5.8 and 7 at seedlings and flowering stages.

Because $99 \%$ of uranium was located in the root of Phaseolus vulgaris and because uranium transfer in root was a rapid process, experiments were conducted on shorter time exposure (about few hours) to understand and quantify uranium - root interactions.

\subsection{Uranium uptake on short term in relation with its bioavailability}

\subsubsection{Effect of $p H$}

There was no saturation mechanism in root uptake up to $3 \mu \mathrm{mol} / \mathrm{L}$ at pHs 5.8 and 7 or $4.9 \mu \mathrm{mol} / \mathrm{L}$ at $\mathrm{pH}$ 4.9. Another experiment was conducted at $\mathrm{pH} 4.9$ up to $21 \mu \mathrm{mol} / \mathrm{L}$ and no saturation phenomenum was evidenced.

Results have even shown that whatever the $\mathrm{pH}$, there was a linear relationship between total uranium concentration in the hydroponic solution and total uranium in roots of Phaseolus vulgaris (figure 2). At $\mathrm{pH} \mathrm{5.8,} \mathrm{where} \mathrm{free} \mathrm{uranyl} \mathrm{ion} \mathrm{content} \mathrm{in} \mathrm{medium} \mathrm{is} \mathrm{less} \mathrm{considerable} \mathrm{than} \mathrm{at} \mathrm{pH} 4.9$, there were other species of uranium uptaken by beans like hydroxocomplexes. So uranium root uptake is not only linked with free ion uranyl but even with other species of uranium in solution and so with total uranium in solution. 


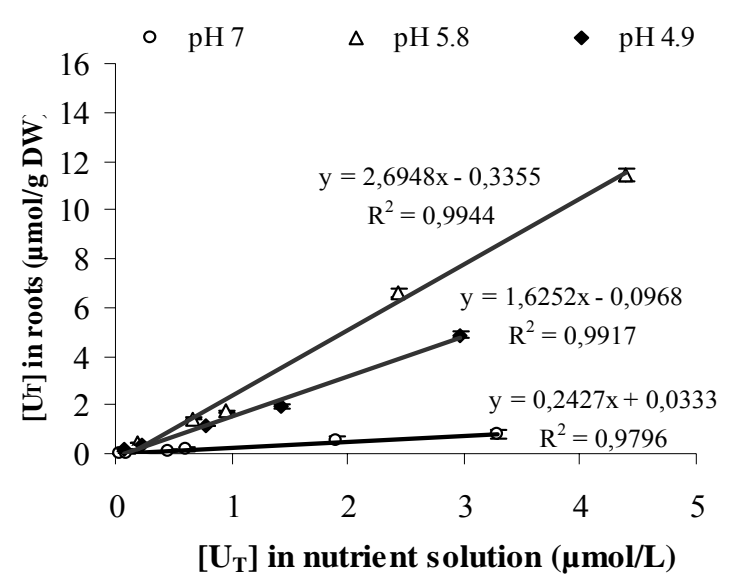

Figure 2. Relationship between total uranium content in roots of Phaseolus vulgaris (mean of 4 replicates) and total uranium concentration in nutrient solution at $3 \mathrm{pHs}$.

Mean TF at the $3 \mathrm{pHs}$ are reported in figure 3. We can observe that at $\mathrm{pH} 7$, where uranyl free ions represent less than $1 \%$ of uranium species in solution, mean TF is greater than at $\mathrm{pH} 4.9(\mathrm{P}<0.05)$. So, uranium uptake by Phaseolus vulgaris seems to be governed by $\mathrm{UO}_{2}{ }^{2+}$ at $\mathrm{pH} 4.9$, hydroxocomplexes $\left(\mathrm{UO}_{2} \mathrm{OH}^{+}\right)$at $\mathrm{pH} 5.8$ or complexes with carbonate at $\mathrm{pH}$ 7. Similar results have been reported by Franklin et al. (2000) [6] between uranium and a tropical freshwater alga (Chlorella sp.). Moreover, at $\mathrm{pH} 4.9, \mathrm{H}^{+}$could compete with free uranyl ion at the root cell surface for available binding sites and diminish root uptake of uranium. Similar results were observed with other metals, such as $\mathrm{Pb}$ [7].

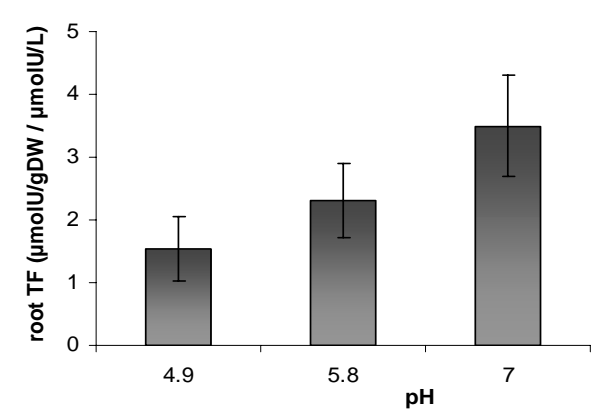

Figure 3. Relationship between mean root Transfer Factor of uranium calculated in a range of uranium concentrations in hydroponic solution and $\mathrm{pH}$ of solution.

\subsubsection{Effect of phosphate}

Increasing phosphate in solution generates a decreasing gradient of free ion $\mathrm{UO}_{2}{ }^{2+}$, whatever the $\mathrm{pH}$. Their complexation behaviour with phosphate was not the same according to the solution $\mathrm{pH}$. Their concentration decreased about $43 \%, 68 \%$ and $12 \%$ at $\mathrm{pH} 4.9,5.8$ and 7 respectively with increasing phosphate concentration in solution from $0 \mu \mathrm{M}$ to $15 \mu \mathrm{M}$. Uranium in roots of 
P. vulgaris was not only governed by free metal concentration in solution. At the pHs 5.8 and 7 , uranium content in roots is greater than $\mathrm{UO}_{2}{ }^{2+}$ content in the medium, whereas at $\mathrm{pH} 4.9$ uranium concentration in roots remain inferior than $\mathrm{UO}_{2}{ }^{2+}$ concentration in the medium. These results indicated that U-phosphate complexes could be bioavailable for P. vulgaris and that there was even a competition phenomena at $\mathrm{pH}$ 4.9. It can even be explained by the free uranium depletion because of its uptake, which change equilibrium near the roots. So roots can act like a strong ligand, which can dissociate uranium-phosphate complexes and only the dissociation of complexe is relevant in uptake and not the entire complexe.

So, despite reduction of ion $\mathrm{UO}_{2}{ }^{2+}$ concentrations, $\mathrm{U}$ uptake by plants was not affected by phosphate treatments (figure 4) whatever $\mathrm{pH}$ and mean $\mathrm{TF}$ values were around $2.5 \mu \mathrm{molU} / \mathrm{gDW} / \mu \mathrm{molU} / \mathrm{L}$.

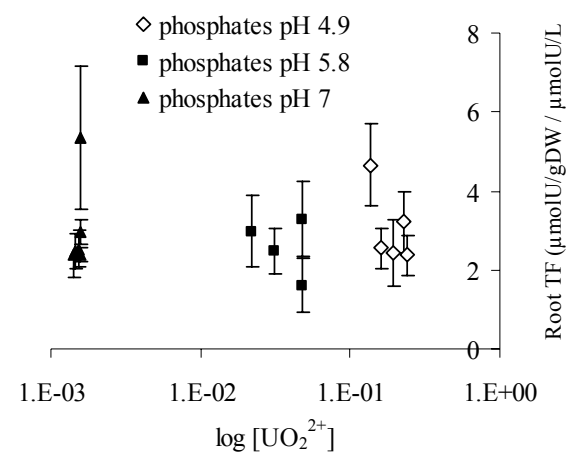

Figure 4. Relationship between root Transfer Factor of uranium and $\mathrm{UO}_{2}{ }^{2+}$ content in nutrient solution in presence of phosphate at $3 \mathrm{pHs}$.

\section{CONCLUSION}

Phaseolus vulgaris translocated only $1 \%$ of the uranium in shoots whatever the $\mathrm{pH}$. Moreover, seedlings stage concentrated more uranium in their tissues than flowering stage.

Uptake of uranium was affected by uranium concentration in the nutrient solution: uranium concentration in roots was increased with increasing total uranium concentration in solution. Reasonable explanation for TF values at $\mathrm{pH} 4.9,5.8$ or 7 is that the uptake of $\mathrm{UO}_{2} \mathrm{OH}^{+}$and $\mathrm{UO}_{2} \mathrm{CO}_{3}$ species in addition to the free uranyl ion $\mathrm{UO}_{2}{ }^{2+}$ was possible. Moreover, the $\mathrm{pH}$ influenced the speciation of uranium but also the competition between $\mathrm{H}^{+}$and $\mathrm{UO}_{2}{ }^{2+}$ for the binding sites on the root surface of $P$. vulgaris. Finally, the presence of ligands in the nutrient solution, such as phosphate, didn't affect uranium uptake by $P$. vulgaris, indicating that U-phosphate complexes were uptaken or that the free metal depletion (moving equilibrium) caused by the uptake contribute to the uranium uptake via dissociation of uranium - phosphate complexes in the bulk solution.

\section{Acknowledgments}

This work is a part of the ENVIRHOM research program funded by the Institute of Radioprotection and Nuclear Safety (IRSN). The authors would like to acknowledge Rodolphe Gilbin for his helpful comments, F. Denison for its help with modelisation. 


\section{References}

[1] Ragnarsdottir K.V., Charlet. L., "Uranium behaviour in natural environments." Mineralogical Society of Great Britain and Ireland, 9 (2000): 333-377.

[2] Campbell, P.G.C. (1995). Interactions between trace metals and aquatic organisms: a critique of the free ion activity model. In Metal Speciation and bioavailability in Aquatic Systems. Eds. A. Tessier and D.R. Turner, pp 45-102. John Wiley \& Sons, New York.

[3] Florence T.M., S. J. L., "Toxicity of copper complexes to the marine diatom Nitzschia closterium." Aquatic Toxicology, 8 (1986): 11-26.

[4] Ebbs S.D., B. D. J., and Kochian L.V., "Role of uranium speciation in the uptake and translocation of uranium by plants." Journal of Experimental Botany 49 (324), (1998): 1183-1190.

[5] Denison F., Application of chemical speciation modelling to uranium toxicity and bioavaibility studies: compilation of a coherent database for simple experimental systems and an investigation of the effect of database uncertainty on model predictions. Report IRSN/DPRE/SERLAB/LRE 02-41 (2002): 162 p.

[6] Franklin N.M., S. J. L., Markich S.J., Lim R.P. "pH-dependent toxicity of copper and uranium to a tropical freshwater alga (chlorella sp.)." Aquatic Toxicology 48, (2002): 275-289.

[7] Slaveykova V.I., a. W. K. J., "Effect of $\mathrm{pH}$ on $\mathrm{Pb}$ biouptake by the freshwater alga Chlorella kesslerii." Environ. Chem. Lett, (2003). 